\title{
Transliteration and transcription effects in biscriptal readers: The case of Greeklish
}

\author{
Maria Dimitropoulou • Jon Andoni Duñabeitia • \\ Manuel Carreiras
}

Published online: 9 April 2011

(C) Psychonomic Society, Inc. 2011

\begin{abstract}
In order to overcome limitations associated with script incompatibilities Greek users of the Internet have developed Greeklish, a transliterated version of Modern Greek using Roman characters. The representational status of this artificial writing system was examined in two masked priming lexical decision experiments using Greeklish primes with different degrees of graphemic overlap with their corresponding Greek targets. Results suggested that Greeklish primes were effectively processed and transliterated to their Greek counterparts. Larger masked priming effects were found as a function of increased prime-target graphemic overlap. Interestingly, these Greeklish priming effects were in all cases of smaller magnitude than the pure Greek identity priming effect. Our findings revealed that extensive experience with a recently developed artificial writing system leads to its non-effortful processing, but that even for highly experienced Greeklish users the Greeklish-
\end{abstract}

\footnotetext{
M. Dimitropoulou $(\bowtie) \cdot J$. A. Duñabeitia $\cdot$ M. Carreiras Basque Center on Cognition, Brain and Language, Paseo Mikeletegi 69, 20009 Donostia, Spain

e-mail: m.dimitropoulou@bcbl.eu
}

M. Dimitropoulou

University of La Laguna,

Tenerife, Spain

M. Carreiras

IKERBASQUE (Basque Foundation for Science),

Bilbao, Spain

M. Carreiras

Departamento de Filología Vasca, University of the Basque Country UPV/EHU,

Bilbao, Spain
to-Greek conversion is modulated by the graphemic properties of the input stimulus.

Keywords Cross-script · Masked priming . Transliterations · Transcriptions

If Archimedes were to communicate his enthusiasm for his discovery that any floating object displaces its own weight of fluid to his Greek peers through an online social network, he would most probably had written "Eyrhka!"

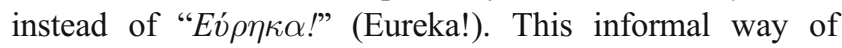
writing Greek words with Roman characters, called Greeklish, has been developed by Greeks in an effort to overcome the software and hardware limitations associated with the use of the Greek alphabet in electronic communication (see also romaji for Japanese). This Greek-toGreeklish conversion (broadly termed transliteration) relies either on the phonemic or the graphemic overlap of a given Greek letter with a Roman one. For the subgroup of letters that sound and look the same across the two alphabets (e.g., $o$ ) and for script-specific graphemes that map onto the same phoneme (e.g., $\varphi-f$, which both map onto /f/), the output of the Greek-to-Greeklish transliteration does not vary. Note, however, that a reduced set of Greek letters can map onto different Roman letters, such as the Greek letter $\omega$, that can be mapped onto $o$ on the basis of the phonemic overlap, or onto $w$ on the basis of a graphemic criterion. This way, Greeklish transliterations usually have extensive phonemic overlap (e.g., $\mu \dot{\eta} \lambda o-m i l o$ [apple] are both pronounced / milo/), while the degree of graphemic overlap can vary

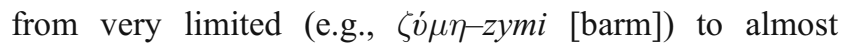

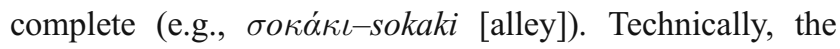
term transliteration refers to the act of representing a given string in a language with a formal representation from a 
different code (e.g., script) following the phoneme-tographeme conversion rules of this new code. If the relations between graphemes and phonemes are similar in both codes, transliterations are considered to be transcriptions. Accordingly, Greeklish conversions with high graphemic overlap with respect to the Greek base words, for which the Roman graphemes sounding the same as the Greek graphemes are visually similar, are better defined as transcriptions. In contrast, when the Roman graphemes associated with the phonemes do not visually resemble those graphemes from the Greek alphabet, the Greeklish conversions are exclusively characterized as transliterations. Well-known instances of transliterations can be found in languages that use multiple writing systems, such as katakana-kanji transliterations of Japanese with extensive phonemic overlap but null graphemic overlap (see Hino, Lupker, Ogawa, \& Sears, 2003). A transcription-transliteration distinction similar to the Greeklish-Greek one is found in the Cyrillic-Roman correspondences that guide Serbian script alternations (e.g., Havelka \& Rastle, 2005); while some of the Roman and Cyrillic graphemes that map onto the same Serbian phoneme are visually very close or identical (transcribed letters; e.g., a-a, b-6), others are visually distinct (transliterated letters; e.g., l-л, с-ц).

In order to ensure the fluidness of the intended virtual communication, it is expected that experienced users of Greeklish would have developed a series of highly internalized processes to perform Greek-to-Greeklish and Greeklish-to-Greek conversions. The present study uses the masked priming paradigm (Forster \& Davis, 1984) to examine the level of automaticity of these conversion processes in Greeks who are exposed to Greeklish on a daily basis. In the masked priming paradigm, a pattern mask is first presented, followed by the brief presentation of a prime (for around $50 \mathrm{~ms}$ ) and then by the target. Crucially, under these conditions participants are unaware of the existence of the prime, while its influence can still be measured on the processing of the target. We used Greek words as targets (e.g., $\varphi \omega ́ \kappa \iota \alpha$ [seal]) and their Greeklish versions as primes (e.g., fwkia) while manipulating their degree of graphemic overlap (transcriptions vs. transliterations). Taking into account the extensive exposure of young Greeks to Greeklish, the multidimensional Greek-Greeklish relation (i.e., a common lexicosemantic representation, almost complete phonemic overlap, and a varying degree of graphemic overlap), and previous reports of cross-script and cross-language masked repetition priming effects (e.g., Gollan, Forster, \& Frost, 1997; Nakamura, Dehaene, Jobert, Le Bihan, \& Kouider, 2007), we expected a Greeklish masked priming effect to emerge.

Given that Greeklish-Greek pairs map onto the same lexicosemantic representation, their processing could resemble that of translation equivalents. Similar to what could be assumed for Greeklish-Greek transliterations or transcriptions, it has been shown that masked primes facilitate the processing of their translation equivalent via the preactivation of the shared meaning (see Duñabeitia, Perea, \& Carreiras, 2010, for a review). However, especially for Greeklish-Greek conversions that have extensive grapho-phonemic overlap-that is, for Greeklish-Greek

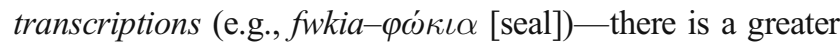
resemblance to translations with extended but not complete graphemic overlap (i.e., nonidentical cognates; e.g., guitar and its Spanish translation, guitarra). These types of translations have been found to lead to larger masked translation priming effects than do nonformally overlapping words (i.e., noncognates; e.g., $d o g$ and its Spanish translation, perro; see, e.g., Duñabeitia et al., 2010). Contrarily, the processing of the Greeklish conversions sharing most of their phonemes but only a very small number of graphemes with their Greek base word - that is, Greeklish-Greek transliterations (e.g., $\beta \lambda \dot{\eta} \mu \alpha-v l i m a$ [missile]) - mostly resembles that of cross-script cognates or of cross-script transliterations (e.g., katakana-kanji for Japanese), which have extensive phonemic but very limited graphemic overlap on top of the semantic overlap (see Hino et al., 2003; Voga \& Grainger, 2007).

In spite of the similarity of Greeklish-Greek pairs to transliterations (or, with translation, equivalents), the fact that Greeklish is a recently created artificial writing system suggests that the sublexical (graphemic and phonemic) overlap across the two codes should be critically involved in the processing of Greeklish items. Previous studies have revealed a clear dissociation between the influences of graphemic and phonemic overlap on the early stages of reading (e.g., Dimitropoulou, Duñabeitia, \& Carreiras, 2011; Grainger \& Holcomb, 2009). In the case of Greeklish reading, the graphemically overlapping letters between Greeklish and Greek could provide a visual cue for the reader to match each Greeklish item to its corresponding Greek word. Alternatively, the extensive and more invariant phonemic overlap across the Greeklish-Greek pairs could also trigger the identification of the correct Greek word upon the presentation of its Greeklish version, similar to how masked phonological priming effects emerge (e.g., brane-BRAIN; Dimitropoulou et al., 2011; see Rastle \& Brysbaert, 2006, for a review).

The present study describes two lexical decision experiments examining Greeklish masked priming effects. Experiment 1 aimed at testing whether the Greeklishto-Greek conversion takes place in an unconscious way in experienced users of Greeklish, by using Greeklish transcriptions as primes and their Greek correspondences as

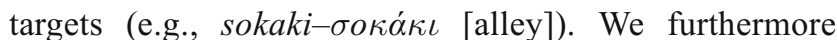
compared the processing of Greeklish transcriptions to that of pure Greek repetitions (e.g., $\sigma o \kappa \alpha ́ \kappa \iota-\sigma o \kappa \alpha \dot{\kappa} \kappa \iota)$. In 
the bilingual literature, comparable repetition priming effects within and across languages have only been obtained with balanced bilinguals, thought to process words from both their languages equally effectively (e.g., Duñabeitia, Dimitropoulou, Uribe-Etxebarria, Laka, \& Carreiras, 2010). Taking into account that Greeklish is only used for specific communication purposes, we expected the Greeklish masked priming effect to be significantly smaller than the Greek identity priming effect, reflecting the fact that even for experienced users of Greeklish, Greek is the dominant linguistic code.

\section{Experiment 1}

Method

Participants Some 44 native Greek speakers with extensive reading and writing exposure to Greeklish completed this experiment (see Table 1 for a full description of the participants' use of Greeklish).

Materials A total of 200 five- and six-letter Greek target words were taken from the GreekLex database (Ktori, van Heuven, \& Pitchford, 2008), and their Greeklish correspondences were obtained. These Greek-Greeklish pairs were transcriptions (not transliterations), given their extensive graphemic and phonemic overlap, measured as the number of visually close or undistinguishable graphemes and the number of shared phonemes. To identify the overlapping graphemes, 20 Spanish college students without any knowledge of the Greek alphabet were asked to indicate which of the Greek lowercase letters could be perceived as known Roman letters. We considered as overlapping those graphemes that were indicated to be visually similar by at least $70 \%$ of the sample (i.e., $\alpha-a, \varepsilon-e, \iota-i, o-o, \tau-t, \kappa-k, \chi-x, \omega-w$ ). The selected Greeklish-Greek repetitions had 70\% and 92\% overlapping graphemes and phonemes, respectively, as measured at the fine-grained level of individual characters. We further corroborated that the strings were graphemically similar at the coarse-grained level by asking another 32
Spanish readers to rate the Greeklish-Greek pairs on a 1-to-5 scale (5 referring to highly similar). The mean similarity score for the pairs was 4.2. The position of the graphemic overlap varied across the prime and target strings. Greek targets (e.g.,

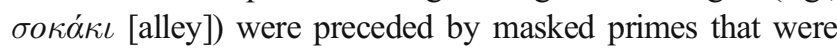

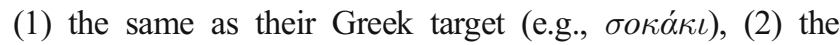
Greeklish transcription of the target (e.g., sokaki), (3) an unrelated Greek word (e.g., $\delta \dot{\alpha} \pi \varepsilon \delta o$ [floor]), or (4) the Greeklish version of the unrelated word (e.g., dapedo). Greek base words used in the unrelated (Greek and Greeklish) conditions were matched as closely as possible to the targets (see Table 2). Furthermore, in order to confirm the extensive use of the Greeklish version of the Greek words, we computed the number of times each precise Greeklish word form had been used in a Greeklish-to-Greek online translator (Chalamandaris, Protopapas, Tsiakoulis, \& Raptis, 2006). Greeklish transcriptions had been used on average more than 300 times, suggesting that they were uniformly accepted as valid Greeklish items. Moreover, ratings on whether each Greeklish transcription was considered the preferred Greeklish version of the target were collected by 20 Greeklish users who did not participate in the experiment. On a 1-to-7 scale (7 representing the "best" Greeklish transcription), the Greeklish transcriptions were rated at 6.9. A set of 200 pronounceable Greek nonwords (e.g., $\pi \alpha \delta \varepsilon \dot{\varepsilon} \mu$ ) was also created. These nonwords were preceded by Greek or Greeklish repetition or unrelated nonword primes. Four lists were constructed so that each target appeared only once in each list, each time in a different priming condition. Different participants were randomly assigned to each list.

Procedure Participants were individually tested in a well-lit soundproof room. The presentation of the stimuli and recording of the responses was carried out using DMDX (Forster \& Forster, 2003). On each trial, a forward mask (i.e., \#\#\#\#\#) was presented for $500 \mathrm{~ms}$. Next, the prime was presented for $50 \mathrm{~ms}$, immediately followed by the target, which remained on the screen for a maximum of 2,500 ms. Primes were presented centered in lowercase 10-pt Courier New font (character width: 0.12 in.), and targets were in lowercase 12-pt Courier New font (character
Table 1 Mean values of exposure and use of Greeklish per week, as calculated by the self-ratingsof the participants of Experiments 1 and 2

\begin{tabular}{llll}
\hline & & Experiment 1 & Experiment 2 \\
\hline Greeklish reading & Hours/week & 13.1 & 13.4 \\
Greeklish writing & Hours/week & 11.2 & 9.2 \\
E-mails in Greeklish & \% received & 44 & 54 \\
& \% sent & 42 & 53 \\
Online messaging in Greeklish & Hours/week & 9.5 & 12 \\
& \% of total time & 79 & 87 \\
Online forums in Greeklish & Hours/week & 7.7 & 5.9 \\
& \% of total time & 66 & 90 \\
\hline
\end{tabular}


Table 2 Examples of the word materials with their lexical properties, as well as mean lexical decision times (RTs, in milliseconds) and error rates $($ Err\%) obtained in Experiment 1

\begin{tabular}{|c|c|c|c|c|c|c|c|}
\hline & \multirow{3}{*}{ 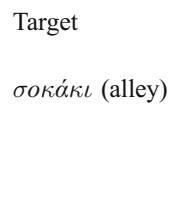 } & \multicolumn{3}{|l|}{ Greek } & \multicolumn{3}{|l|}{ Greeklish } \\
\hline & & \multicolumn{2}{|l|}{ Primes } & \multirow{2}{*}{$\begin{array}{l}\text { Effect } \\
\text { UR - R }\end{array}$} & \multicolumn{2}{|l|}{ Primes } & \multirow{2}{*}{$\begin{array}{l}\text { Effect } \\
\text { UR - T }\end{array}$} \\
\hline & & 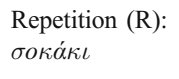 & $\begin{array}{l}\text { Unrelated (UR): } \\
\delta \alpha \dot{\pi} \varepsilon \delta o \text { (floor) }\end{array}$ & & $\begin{array}{l}\text { Transcription }(\mathrm{T}) \text { : } \\
\text { sokaki }\end{array}$ & $\begin{array}{l}\text { Unrelated (UR): } \\
\text { dapedo }\end{array}$ & \\
\hline Frequency & 22 & 22 & 21 & & 22 & 21 & \\
\hline Length & 5.7 & 5.7 & 5.7 & & 5.7 & 5.7 & \\
\hline Graph. overlap & - & $5.7(100 \%)$ & $0.0(0 \%)$ & & $4.0(70 \%)$ & $0.0(0 \%)$ & \\
\hline Phon. overlap & - & $5.7(100 \%)$ & $0.0(0 \%)$ & & $5.2(92 \%)$ & $0.0(0 \%)$ & \\
\hline RTs & & $659(16.1)$ & $699(15.6)$ & $40(5.3)$ & $677(15.3)$ & $692(16.5)$ & $15(4.5)$ \\
\hline Err\% & & $3.8(0.7)$ & $4.3(0.6)$ & $0.5(0.7)$ & $4.0(0.5)$ & $4.0(0.6)$ & $0.0(0.7)$ \\
\hline
\end{tabular}

Graphemic overlap and phonemic overlap are given as the mean number of position-specific common graphemes or phonemes between primes and targets. Mean percentages of overlap or reaction time and error rate standard errors are presented within parentheses. The mean reaction times

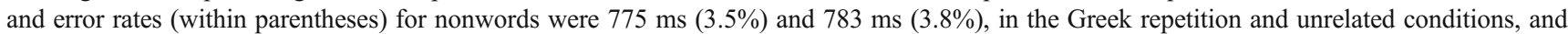
$786 \mathrm{~ms}(4.3 \%)$ and 782(3.7\%), in the Greeklish repetition and unrelated conditions. Graph., Graphemic; Phon., Phonemic

width: 0.16 in.), in order to avoid overlapping pixels. Participants were instructed to press, as quickly and accurately as possible, one of two buttons on the keyboard to indicate whether the target was a legitimate Greek word or not. They were not informed of the presence of the primes, and none of them reported conscious knowledge of the primes' existence. Trial presentation was randomized across participants. Each participant received a total of 12 practice trials ( 6 words and 6 nonwords). The experimental session lasted approximately $15 \mathrm{~min}$.

\section{Results and discussion}

Incorrect responses and reaction times shorter than $250 \mathrm{~ms}$ or greater than $1,500 \mathrm{~ms}$ (less than $2.5 \%$ of the word data) were excluded from the analysis. Mean latencies for correct responses and mean error rates are presented in Table 2. ANOVAs on reaction times and error rates by participants and items were conducted based on a 2 (type of relationship: repetition/unrelated) $\times 2$ (script: Greek/Greeklish $) \times 4$ (list: $1 /$ 2/3/4) design.

The ANOVAs on reaction times revealed a main effect of type of relationship: Targets were responded to faster $(28 \mathrm{~ms})$ when preceded by related primes than when preceded by unrelated primes, $F_{1}(1,40)=106.08, p<.001 ; F_{2}(1,196)=$ $54.37, p<.001$. The main effect of script was not significant (a 6-ms difference; both $p s>.13$ ). Critically, the interaction between the two factors was significant, $F_{1}(1,40)=15.37$, $p<.001 ; F_{2}(1,196)=10.98, p<.01$. Subsequent pairwise comparisons showed faster responses (by $40 \mathrm{~ms}$ ) to targets primed by their exact Greek repetitions, as opposed to by unrelated Greek primes, $F_{1}(1,40)=77.41, p<.001 ; F_{2}(1$, $196)=48.73, p<.001$. Targets were also responded to faster (by $15 \mathrm{~ms}$ ) when primed by their Greeklish transcriptions than by unrelated Greeklish primes, $F_{1}(1,40)=18.55, p<.001$; $F_{2}(1,196)=9.37, p<.01$, even though the magnitude of the identity priming effect was significantly larger than that of the Greeklish priming effect (a 25-ms difference).

ANOVAs on the arcsine-transformed ${ }^{1}$ error rates did not reveal any significant effects (all $p \mathrm{~s}>.11$ ).

The nonword data did not reveal any significant effects (all $p \mathrm{~s}>.13)$.

Experiment 1 showed a significant masked identity priming effect with Greek primes, as well as a Greeklish masked priming effect with Greeklish transcriptions, suggesting that for experienced users of Greeklish, the Greeklish-toGreek conversion takes place in a ballistic and unconscious manner. However, the significant difference in the magnitude of the Greeklish-Greek and Greek-Greek priming effects suggests that Greeklish transcriptions activate their Greek correspondences less effectively than do Greek repetition primes. We interpret this difference as reflecting a distinction at the graphemic level of processing, since the graphemic overlap was not total $(70 \%)$, while the phonemic overlap was almost complete (92\%). A strong graphemic component in the Greeklish masked priming effect would predict that under similar circumstances, Greeklish transcriptions should lead to larger Greeklish masked priming effects than would Greeklish transliterations, due to the increased graphemic overlap. Experiment 2 was designed to address this issue by examining Greeklish masked priming effects produced by Greeklish transcriptions and transliterations.

\footnotetext{
${ }^{1}$ We opted for using the arcsine transformation due to the fact that a large part of the error data were gathered near the lower limit of the percentage range $(0 \%)$, thus violating ANOVA's assumption of the free variation of data around the mean (see Jaeger, 2008).
} 


\section{Experiment 2}

Method

Participants A different group of 46 native Greek speakers with extensive exposure to Greeklish and matched to the group who completed Experiment 1 took part in this Experiment (see Table 1).

Materials A total of 200 five-letter Greek targets were selected from the GreekLex database. Following the results of the questionnaires described in Experiment 1, these words were divided in two groups: a transliteration group, if they had only 1-2 graphemes in common with their Greeklish counterpart (mean of 30\% graphemic overlap; e.g., $\beta \lambda \eta \mu \alpha-v$ lima [missile]), and a transcription group, if they had 3-4 common graphemes (mean of 70\% graphemic overlap; e.g., fwkia- $\phi \omega ́ \kappa \iota \alpha$ [seal]). To avoid providing a processing advantage for either transcriptions or transliterations due to uneven distributions of onset overlap, none of the transcription or transliteration Greeklish-Greek pairs selected overlapped in their initial grapheme. Each Greek target was preceded by (1) its Greeklish transliteration/transcription or by (2) a semantically and formally unrelated but otherwise matched Greeklish word (see Table 3). The same procedure used in Experiment 1 was followed to validate the quality of the Greeklish items according to the Greeklish-to-Greek online translator. Converted Greeklish forms from the transcribed and transliterated groups had been used on average more than 230 times by expert Greeklish users $(p>.85)$. According to the offline questionnaires, the appropriateness of the Greeklish transliteration/transcription primes was rated with 6.5 in the 1-to-7 scale. An additional set of 200 five-letter
Greek pronounceable nonwords was also created, which were presented preceded by Greeklish related and unrelated primes. The priming conditions and materials were counterbalanced in two lists, and different participants were randomly assigned to each of the lists.

Procedure The same procedure was followed as in Experiment 1.

\section{Results and discussion}

Less than $1.5 \%$ of the word data were excluded from the analysis following the same data trimming procedure as in Experiment 1. Mean latencies for correct responses and mean error rates are presented in Table 3. ANOVAs on the reaction times and error rates by participants and by items were conducted based on a 2 (degree of overlap: transcription/ transliteration $) \times 2$ (type of relationship: related/unrelated $) \times$ 2 (list: 1/2) design.

ANOVAs on the reaction times revealed a main effect of type of relationship: Participants responded faster to the targets $(20 \mathrm{~ms})$ when primed by their Greeklish counterparts than when primed by unrelated Greeklish forms, $F_{1}(1,44)=29.23, p<.001 ; F_{2}(1,98)=29.75, p<$ .001. A main effect of degree of overlap (marginally significant in the $F_{2}$ analysis) was also found, showing that targets in the transcription group were responded to faster $(16 \mathrm{~ms})$ than targets in the transliteration group, $F_{1}(1,44)=18.59, p<.001$; $F_{2}(1,98)=3.45, p=.07$. Importantly, the two factors significantly interacted with each other, $F_{1}(1,44)=4.53, p<$ $.05 ; F_{2}(1,98)=4.81, p<.05$. Despite the significant relatedness effect found for the transliterated group (12 ms) $\left[F_{1}(1,44)=5.52, p<.05 ; F_{2}(1,98)=10.48, p<.01\right]$, the

Table 3 Examples of the word materials with their lexical properties, as well as mean lexical decision times (RTs, in milliseconds) and error rates $($ Err\%) obtained in Experiment 2

\begin{tabular}{|c|c|c|c|c|c|c|c|c|}
\hline & \multicolumn{4}{|c|}{ Transliteration (Low Graphemic Overlap) } & \multicolumn{4}{|c|}{ Transcription (High Graphemic Overlap) } \\
\hline & \multirow{2}{*}{$\begin{array}{l}\text { Target } \\
\beta \lambda \dot{\eta} \mu \alpha \\
\text { (missile) }\end{array}$} & \multicolumn{2}{|c|}{ Greeklish Primes } & \multirow{2}{*}{$\begin{array}{l}\text { Effect } \\
\text { UR - R }\end{array}$} & \multirow{2}{*}{$\begin{array}{l}\text { Target } \\
\varphi \omega ́ \kappa \iota \alpha \\
\text { (seal) }\end{array}$} & \multicolumn{2}{|c|}{ Greeklish Primes } & \multirow{2}{*}{$\begin{array}{l}\text { Effect } \\
\text { UR - R }\end{array}$} \\
\hline & & $\begin{array}{l}\text { Related (R): } \\
\text { vlima }\end{array}$ & $\begin{array}{l}\text { Unrelated (UR): } \\
\text { tafos (grave) }\end{array}$ & & & $\begin{array}{l}\text { Related (R): } \\
\text { fwkia }\end{array}$ & $\begin{array}{l}\text { Unrelated (UR): } \\
\text { stani (sheepfold) }\end{array}$ & \\
\hline Frequency & 18 & 18 & 16 & & 17 & 17 & 16 & \\
\hline Length & 5 & 5 & 5 & & 5 & 5 & 5 & \\
\hline Graph. overlap & - & $1.5(30 \%)$ & $0.0(0 \%)$ & & - & $3.5(70 \%)$ & $0.0(0 \%)$ & \\
\hline Phon. overlap & - & $4.3(87 \%)$ & $0.3(1 \%)$ & & - & $4.4(88 \%)$ & $0.0(0 \%)$ & \\
\hline RTs & & $695(14.1)$ & $707(14.4)$ & $12(5.0)$ & & $703(13.5)$ & $731(14.4)$ & $28(5.0)$ \\
\hline Err\% & & $4.4(0.6)$ & $3.8(0.6)$ & $-0.6(0.6)$ & & $7.1(0.8)$ & $6.5(1.0)$ & $-0.6(0.7)$ \\
\hline
\end{tabular}

Graphemic overlap and phonemic overlap are given as the mean number of position-specific common graphemes or phonemes between primes and targets. Mean percentages of overlap and reaction time and error rate standard errors are presented within parentheses. The mean reaction times and error rates (within parentheses) for nonwords were $776 \mathrm{~ms}(2.6 \%)$ and $779 \mathrm{~ms}(2.9 \%)$ in the related and unrelated conditions, respectively. Graph., Graphemic; Phon., Phonemic 
relatedness effect found for the transcribed group was significantly larger $(28 \mathrm{~ms})\left[F_{1}(1,44)=27.29, p<.001\right.$; $\left.F_{2}(1,98)=22.63, p<.001\right]$.

ANOVAs on the arcsine-transformed error rates revealed a main effect of degree of overlap, $F_{1}(1,44)=31.55, p<.001$; $F_{2}(1,98)=5.04, p<.05$. The rest of the effects were not significant (all $p \mathrm{~s}>.17$ ).

ANOVAs on the nonword data did not reveal any significant effects (all $p \mathrm{~s}>.32$ ).

Experiment 2 replicated the Greeklish masked priming effect with both transcriptions and transliterations, despite the differing graphemic overlaps. Interestingly, the results showed a graded pattern induced by the increased graphemic similarity of transcriptions as opposed to transliterations. These findings suggest that the magnitude of the Greeklish priming effect is directly proportional to the number of overlapping graphemes between related primes and targets, and they reveal the existence of a strong graphemic component in the Greeklish masked priming effect.

\section{General discussion}

The present study examined the level of automaticity of the conversion of romanized (Greeklish) transliterated and transcribed versions to their corresponding Greek words, as well as the extent to which this process is influenced by graphemic overlap. To this end, Greek targets were presented briefly preceded by their Greeklish versions, with extensive phonemic overlap but varying degrees of graphemic overlap (transcriptions vs. transliterations). In Experiment 1, experienced users of Greeklish showed a significant Greeklish masked priming effect for pairs with high graphemic overlap (transcriptions), which was in turn smaller than the Greek identity priming effect. With a similar sample of Greeklish users, Experiment 2 revealed larger priming effects for transcriptions than for transliterations (high vs. low graphemic overlap, respectively), underlining the strong sublexical/graphemic component of the Greeklish effect.

The overall pattern of Greeklish masked priming effects closely resembles the one reported with transliterations (e.g., kana-kanji for Japanese). Further, the magnitude difference between the Greek-Greek and Greeklish-Greek repetition priming effects found in Experiment 1 is highly similar to the pattern obtained by Nakamura et al. (2007), who found that priming effects for kanji-kanji repetitions were larger than those for kana-kanji transliterations among Japanese speakers who were more familiar with the kanji than with the kana writing system.

In Experiment 2, we obtained a clear-cut graded pattern of Greeklish masked priming effects that was strongly modu- lated by the amount of graphemic overlap (transcriptions vs. transliterations). A similar influence of graphemic overlap has been previously reported in bilingual studies testing masked translation priming effects, where larger effects have been reported for cognates as compared to noncognates (Duñabeitia et al., 2010), as well as for cognates with increased formal overlap as compared to cognates with less overlapping units (Voga \& Grainger, 2007).

The overall pattern of Greeklish masked priming effects indicates that graphemic overlap is a prerequisite for their appearance and that priming effects for highly overlapping transcriptions such as $f w k i a-\varphi \omega ́ \kappa \iota \alpha$ are larger than those for less overlapping transliterations such as vlima- $\beta \lambda \dot{\eta} \mu \alpha$. Intuitively, one might argue that the Greeklish priming effects obtained follow the same regularization mechanisms that govern the LEET priming effects obtained with repetition primes containing letterlike symbols or numbers (e.g., M4T3R14L-MATERIAL; Carreiras, Duñabeitia, \& Perea, 2007; Kinoshita \& Lagoutaris, 2010; Molinaro, Duñabeitia, Marín-Gutiérrez, \& Carreiras, 2009). LEET effects have been proposed to result from a regularization process of the features of the letterlike characters (e.g., numbers or symbols) embedded in the primes, driven by the complete match between the prime-target letters (e.g., Carreiras et al., 2007; Molinaro et al., 2009). Nonetheless, even though such a feature-based regularization process could be involved in the enhanced transcription (high graphemic overlap) Greeklish effect, it cannot be considered to be entirely driving all of the observed Greeklish effects, since significant effects were obtained not only for transcriptions but also for transliterations (with low graphemic overlap), in which $70 \%$ of the units were mismatching between prime and target. In turn, we believe that the origin of Greeklish priming effects stems from grapheme (not feature) overlap, localized at a more abstract level of case-specific representations involving size, font, color, position, and orientation-invariant letter representations (e.g., Dehaene, Cohen, Sigman, \& Vinckier, 2005). ${ }^{2}$ This proposal is based on evidence showing that masked repetition priming effects are insensitive to feature overlap (i.e., the same amount of repetition priming is typically found for pairs with high and low feature overlap, such as kiss-KISS and gear-GEAR; see Kinoshita \& Kaplan, 2008, for a review).

\footnotetext{
${ }^{2}$ Given that the Greeklish priming effects were obtained with samecase (lowercase) Greeklish-Greek prime-target pairs, we can only assume the involvement of case-specific graphemic representations in the appearance of the effects. Future research testing the persistence of the effects when Greeklish primes and Greek targets are presented in different cases could identify whether these graphemic representations are situated higher in the orthographic processing stream, at a caseindependent level of abstract letter identities. The authors thank an anonymous reviewer for bringing this possibility to our attention.
} 
Critically, in both experiments the phonemic overlap across the Greeklish-Greek repetitions was nearly complete (above 85\%). Although it has been shown that masked phonological priming effects can be obtained even when the graphemic overlap is nonexistent and the phonemic overlap is incomplete (e.g., Dimitropoulou et al., 2011; Rastle \& Brysbaert, 2006), the difference in the magnitude of the Greeklish priming effects for transcriptions and transliterations suggests that the Greeklish effect is mainly driven by the graphemic and not by the phonemic overlap. This proposal provides support to the so-called "weak phonological theory," which in contrast to theories of "strong phonology" (Frost, 2003), posits that the early stages of visual word recognition depend on the orthographic, and to a lesser extent on the phonological, properties of the input stimulus (e.g., Coltheart, Rastle, Perry, Langdon, \& Ziegler, 2001). Current research in our lab is aimed at obtaining evidence regarding the influence of phonemic overlap and its interaction with graphemic overlap in the overall pattern of Greeklish priming effects, by testing Greeklish-Greek pairs with limited phonemic overlap and extensive graphemic overlap.

In summary, our results provide a first approximation of the processing of a recently developed artificial writing system (Greeklish). We present evidence showing that words written in Greeklish are unconsciously processed and that they effectively activate the lexicosemantic representations of real Greek words. However, this activation depends on the graphemic overlap between the Greeklish-Greek strings, showing for the first time that transcriptions are more effectively processed than transliterations.

Acknowledgements M.D. was the recipient of a postgraduate grant from the Government of the Canary Islands. This research was partially supported by CONSOLIDER-INGENIO 2010 (CSD200800048) and SEMA (PSI 2009-08889) Grants from the Spanish Ministry of Science and Innovation. Special thanks are due Jonathan Leavitt. The authors also thank Athanasios Protopapas for his insightful comments and for his help in running part of this study, as well as Aimilios Chalamandaris and the Institute of Language and Speech Processing (ILSP, Athens, Greece) for their collaboration.

\section{References}

Carreiras, M., Duñabeitia, J. A., \& Perea, M. (2007). READING WORDS, NUMB3R5 and \$YM $30 L \$$. Trends in Cognitive Sciences, 11, 454-455.

Chalamandaris, A., Protopapas, A., Tsiakoulis, P., \& Raptis, S. (2006). All Greek to me! An automatic Greeklish to Greek transliteration system. Paper presented at the 5th International Conference on Language Resources and Evaluation (LREC 2006), Genoa, Italy.

Coltheart, M., Rastle, K., Perry, C., Langdon, R., \& Ziegler, J. C. (2001). DRC: A dual route cascaded model of visual word recognition and reading aloud. Psychological Review, 108, 204-256.
Dehaene, S., Cohen, L., Sigman, M., \& Vinckier, F. (2005). The neural code for written words: A proposal. Trends in Cognitive Sciences, 9, 335-341.

Dimitropoulou, M., Duñabeitia, J. A., \& Carreiras, M. (2011). Phonology by itself: Masked phonological priming effects with and without orthographic overlap. Journal of Cognitive Psychology, 23, 185-203.

Duñabeitia, J. A., Dimitropoulou, M., Uribe-Etxebarria, O., Laka, I., \& Carreiras, M. (2010). Electrophysiological correlates of the masked translation priming effect with highly proficient simultaneous bilinguals. Brain Research, 1359, 142-154.

Duñabeitia, J. A., Perea, M., \& Carreiras, M. (2010). Masked translation priming effects with highly proficient simultaneous bilinguals. Experimental Psychology, 57, 98-107.

Forster, K. I., \& Davis, C. (1984). Repetition priming and frequency attenuation in lexical access. Journal of Experimental Psychology. Learning, Memory, and Cognition, 10, 680-698.

Forster, K. I., \& Forster, J. C. (2003). DMDX: A Windows display program with millisecond accuracy. Behavior Research Methods, Instruments, \& Computers, 35, 116-124.

Frost, R. (2003). The robustness of phonological effects in fast priming. In S. Kinoshita \& S. J. Lupker (Eds.). Masking Priming the State of the Art. The Macquarie Monographs in Cognitive Science, Hove, UK: Psychology Press.

Gollan, T. H., Forster, K. I., \& Frost, R. (1997). Translation priming with different scripts: Masked priming with cognates and noncognates in Hebrew-English bilinguals. Journal of Experimental Psychology. Learning, Memory, and Cognition, $23,1122-1139$.

Grainger, J., \& Holcomb, P. J. (2009). Watching the word go by: On the time-course of component processes in visual word recognition. Language and Linguistics Compass, 3, 128-156.

Havelka, J., \& Rastle, K. (2005). The assembly of phonology from print is serial and subject to strategic control: Evidence from Serbian. Journal of Experimental Psychology. Learning, Memory, and Cognition, 31, 148-158.

Hino, Y., Lupker, S. J., Ogawa, T., \& Sears, C. R. (2003). Masked repetition priming and word frequency effects across different types of Japanese scripts: An examination of the lexical activation account. Journal of Memory and Language, 48, 33-66.

Jaeger, T. F. (2008). Categorical data analysis: Away from ANOVAs (transformation or not) and towards logit mixed models. Journal of Memory and Language, 59, 434-446.

Kinoshita, S., \& Kaplan, L. (2008). Priming of abstract letter identities in the letter match task. The Quarterly Journal of Experimental Psychology, 61, 1873-1885.

Kinoshita, S., \& Lagoutaris, S. (2010). Priming by NUMB3R5 does not involve top-down feedback. Journal of Experimental Psychology. Learning, Memory, and Cognition, 36, 1422-1440.

Ktori, M., van Heuven, W. J. B., \& Pitchford, N. J. (2008). GreekLex: A lexical database of modern Greek. Behavior Research Methods, 40, 773-783.

Molinaro, N., Duñabeitia, J. A., Marín-Gutiérrez, A., \& Carreiras, M. (2009). From numbers to letters: Feedback regularization in visual word recognition. Neuropsychologia, 48, 1343-1355.

Nakamura, K., Dehaene, S., Jobert, A., Le Bihan, D., \& Kouider, S. (2007). Subliminal convergence of Kanji and Kana words: Further evidence for functional parcellation of the posterior temporal cortex in visual word recognition. Journal of Cognitive Neuroscience, 17, 954-968.

Rastle, K., \& Brysbaert, M. (2006). Masked phonological priming effects in English: Are they real? Do they matter? Cognitive Psychology, 53, 97-145.

Voga, M., \& Grainger, J. (2007). Cognate status and cross-script translation priming. Memory \& Cognition, 35, 938-952. 